\title{
Community-level Mental Health and Psychosocial Support During Armed Conflict: A Cohort Study from the Democratic Republic of Congo, Mali and Nigeria
}

Ida Andersen ( $\square$ iandersen@icrc.org )

International Committee of the Red Cross (ICRC) https://orcid.org/0000-0001-8669-8478

Rodolfo Rossi

ICRC- Red Cross: International Committee of the Red Cross

Ives Hubloue

Vrije Universiteit Brussel - Campus Jette: Vrije Universiteit Brussel - Brussels Health Campus

\section{Research}

Keywords: ICRC, MHPSS, Africa, Conflict, Sexual Violence

Posted Date: November 17th, 2021

DOI: https://doi.org/10.21203/rs.3.rs-1049021/v1

License: (c) (i) This work is licensed under a Creative Commons Attribution 4.0 International License.

Read Full License

Version of Record: A version of this preprint was published at Frontiers in Public Health on March 28th, 2022. See the published version at https://doi.org/10.3389/fpubh.2022.815222. 


\section{Abstract}

Introduction: Community-level mental health and psychosocial support (MHPSS) was the first type of MHPSS program launched by the International Committee of the Red Cross (ICRC) back in 2004. Standardized beneficiary-level monitoring was put in place in late 2018. This is the first study to explore whether this type of program correlates, as intended, with reduced psychological distress and increased daily functioning.

Methods: Between December 2018 and June 2020, 6,413 victims of violence received MHPSS through 32 community-level projects in the Democratic Republic of Congo, Mali and Nigeria. Symptoms of psychological distress (IES-R or DASS21) and daily functioning (ICRC scale) were assessed before and after the intervention and logistical regression models were used to identify predictors of these symptoms.

Results: The most predominant perpetrators were weapon-bearers (76\%) and the most common type of violence was rape (46\%). Victims of violence committed by weapon-bearers were more likely to show high levels of anxiety prior to MHPSS (aOR $3.51 ; p<0.0001$ ). Also, victims of physical violence were more likely to show high levels of stress (aOR 1.49; $p<0.0001$ ) whereas victims who had witnessed physical violence were more like to report high levels of depression (aOR $2.54 ;<0.0001)$. Lack of social support stood out as a predictor of both high anxiety (aOR 2.10; $<<0.0001)$ and post-traumatic stress (aOR 2.04; $p<0.0001)$ prior to MHPSS. Following MHPSS, the vast majority of beneficiaries reported a reduction in distress on the DASS21 (96.58\%) and the IES-R scales (92.70\%) as well as an increase of functioning (82.26\%). Adherence to group therapy ( 7 sessions on average) was stronger than individual therapy (4 sessions on average). A linear trend was found between length of treatment and likelihood of reporting reduced symptoms of depression. Having suffered destruction or loss of property or income was predicted less improvement of functioning following MHPSS (aOR 0.90; $p=0.044$ ).

Conclusion: Community-level MHPSS is associated with increased well-being among the vast majority of beneficiaries. To further increase intended health outcomes, it is recommended to increase the number of sessions per beneficiary and address, where relevant, the financial consequences of violence. Also, a longitudinal study is recommended to assess the longer-term changes in symptoms.

\section{Introduction}

\section{Community-level MHPSS in the ICRC}

For more than 150 years, the International Committee of the Red Cross (ICRC) has offered humanitarian protection and assistance to victims of armed conflict and other situations of violence. Mental health and psychosocial support (MHPSS) is one of the most recent additions to the wide-ranging assistance programs of the ICRC and aims to address the specific MHPSS consequence of violence, including sexual violence. 
Community-level MHPSS for victims of violence was the first type of MHPSS program launched by the ICRC. Starting with the maisons d'écoute counseling centers in the Democratic Republic of Congo (DRC) in 2004, similar types of projects are now running in 15 countries worldwide and reached more than 32.000 direct beneficiaries in 2020 .

Community-level MHPSS programs are implemented in collaboration with a local partner such as a local association, non-government organization or the Red Cross Red Crescent national society. These programs are part of a larger effort to holistically address the needs of victims of violence which can include:

- Health: Medical care including Clinical Management of Rape and MHPSS.

- Economic Security. Cash-transfers, microeconomic initiatives and/or other income-generating activities for victims having suffered important financial consequences as a result of violence.

- Water and Habitat. Constructing or rehabilitating the facilities of the community partner to ensure a confidential counseling room as well as accommodation for certain victims.

- Protection: Interviews with victims to document potential violations of International Humanitarian Law $(\mathrm{IHL})$ followed in some instances by a confidential dialogue with the commanders of the alleged perpetrators aiming at preventing further violence.

- Prevention: IHL dissemination sessions with weapon-bearers.

\section{From monitoring outputs to conducting operational research}

Initially, the monitoring of ICRC MHPSS programs was highly budget-oriented and limited to outputs such as "number of trainings organized". In 2008, the ICRC introduced the results-based management approach which shifted focus to the outcomes of each humanitarian project, such as "percentage of participants who improved their knowledge" following a training.

The "Framework for monitoring and evaluation of MHPSS programs in emergency settings", published by the Inter-Agency Standing Committee (IASC) in 2017 intensified efforts at a global level to improve and harmonize MHPSS monitoring and evaluation tools. Within the Red Cross Red Crescent Movement ("Movement"), the International Federation of Red Cross Red Crescent Societies (IFRC) published a "Monitoring and Evaluation Framework for Psychosocial Support Interventions" in 2017 targeting National Red Cross Red Crescent Societies.

Similarly, in 2018, the ICRC MHPSS team adopted an electronic case management system with standardized monitoring tools, such as intake forms and psychometric scales, that made it possible to track the evolution of each direct beneficiary before, during and after MHPSS care. 
These initiatives lay the foundation for the Movement "Policy on Addressing Mental Health and Psychosocial Needs" adopted during the 33rd International Conference in December 2019. One of the policy's eight statements is devoted to ensuring that MHPSS programs are "informed by evidence", "ensure quality of care" and that the Movement "contributes, where possible, to data collection [and] research".

The present study would not have been possible without this immense work of improving and harmonizing ICRC MHPSS monitoring tools. It aims to walk the talk in terms of carrying out operational research to inform practice and contribute to the evidence base for MHPSS programs in conflict settings.

\section{The MHPSS pyramid of the International Red Cross Red Crescent Movement}

While the IASC MHPSS pyramid is intended for emergency settings, the MHPSS Movement pyramid is intended for all contexts. It contains four different layers (figure 1).

First, basic psychosocial support which targets $100 \%$ of a population affected by violence and seeks to promote resilience by raising awareness, for example, on common MHPSS consequences of exposure to violence, including sexual violence, and locally available services. In DRC, Mali and Nigeria, partner organizations such as local associations or the national Red Cross society are trained and supervised by ICRC MHPSS teams to carry out awareness raising activities in selected areas on themes of relevance to the context.

Second, focused psychosocial support aims to prevent the development of more severe mental health consequences of exposure to violence. In Nigeria, ICRC MHPSS teams train and supervise national society volunteers to conduct group sessions for victims of violence that include a peer support component in which the participants learn from one another.

Third, psychological support is the predominant layer in ICRC MHPSS programs for victims of violence at community level. It addresses the needs of victims of violence that present more severe psychological distress and involves individualized counseling and/or group interventions. In DRC and Mali, the ICRC MHPSS teams train and supervise partner organizations such as local associations or the national Red Cross society to assess the unique difficulties of each beneficiary in terms of psychological distress and daily functioning using psychometric tools. A treatment plan is defined, and the beneficiary is offered individual counselling sessions. In Nigeria, the group sessions offered in collaboration with the Nigerian Red Cross also target the psychological needs of victims of violence and use similar psychometric monitoring tools.

Fourth, specialized mental health care involve highly advanced psychological and psychiatric services. In DRC, Mali and Nigeria the ICRC does not offer these services directly but aims to refer victims of violence for whom the three lower levels of MHPSS care do not suffice to specialized services available through the Ministries of Health or other actors. 


\section{Research question}

In this study, we look specifically at the psychological support layer of community-level MHPSS programs by examining the data available from the ICRC's clinical work with victims of violence at community level in DRC, Mali and Nigeria. The aim is two-fold: first, to identify predictors of high psychological distress and low functioning prior to psychological support and, second, to identify predictors of reduced distress and increased functioning following psychological support.

\section{Methods}

\section{Study design}

This is a non-controlled retrospective cohort study of 6,413 victims of violence who received psychological support between December 2018 and June 2020 through 32 community projects in DRC, Mali and Nigeria. The data was collected routinely for clinical follow-up and internal monitoring purposes.

\section{Target population}

The target population of ICRC community-level MHPSS programs consists of civilian men, women, boys and girls directly affected by armed conflict or other situations of violence. According to the ICRC's mandate, these programs are set up in areas where violence is committed mainly by weapon-bearers. Thus, they target victims of a form of violence that could be considered a breach of IHL, i.e., the principle of distinction that prohibits indiscriminate attacks affecting the civilian population ${ }^{12}$.

Psychological support is offered to victims that present particularly high levels of psychological distress and low functioning as a result of exposure to violence.

\section{The Intervention}

\section{Pre-assessment:}

To evaluate the pertinence of offering psychological support and prepare an individualized treatment plan, levels of psychological distress are assessed using either the Depression, Anxiety and Stress Scale with 21 items (DASS21) or the Impact of Events Scale Revised (IES-R). In addition, the ICRC functioning scale is used to estimate the level of daily functioning of each beneficiary ${ }^{13}$ (figure 2).

\section{Individual psychological support:}


Victims of violence in DRC and Mali receive individual psychological support by lay counselors called agents psychosociaux (APS) who are trained and supervised by the ICRC MHPSS team. As described in a previous publication ${ }^{14}$, a short-term solution-oriented approach is adopted to empower the beneficiary to reflect upon and resolve his or her specific problems. In addition to offering psychological support, referrals to local service providers are made according to needs and availability. Some counseling centers can also accommodate briefly those victims of violence who live far from the counseling center, who are facing family disputes, stigma or other difficulties preventing them from returning to their homes.

\section{Group_psychological support:}

Victims of violence in Nigeria receive grOup psychological support by ICRC-trained lay counselors working for the Nigerian Red Cross Society (NRCS). After one or several individual preparatory sessions that allow the counselors to get to know the beneficiaries and group them according to their profiles, ten group sessions are organized, focusing on the following themes:
i. Introduction
ii. Loss \& Grief
iii. Flashbacks and Intrusive Memories
iv. Sleep \& Nightmares
v. Anger \& Irritability
vi. Psychosomatic Pain
vii. Guilt and Self-Blame
viii. Family Problems
ix. Summary
x. Closure \& Post-evaluations

Each session includes a strong psychoeducational component and introduces the participants to adaptive coping skills.

Post assessments: Following the psychological support, levels of psychological distress and daily functioning are assessed once again, using the same psychometric tools as during the pre-assessment phase.

\section{Dataset}

The following variables from the dataset were used in the study: 


\section{Demographic information:}

country, gender, age, civil status, resident/migrant/internally displaced, education level, occupation and number of children.

\section{Type of violence experienced:}

Victim of physical violence (excluding rape, attempted rape and torture), Witness of physical violence, Rape, Attempted rape, Incest, Forced marriage, Forced prostitution, Victim of trafficking/smuggling, Kidnapping/hostage taking including sexual violence, Kidnapping/hostage taking excluding sexual violence, Killing of a loved one, Disappearance of a loved one, Forced recruitment, Torture/ill-treatment, Insults/threats, Other.

\section{Place of violence:}

Home, School/Work, On the road/While going somewhere, During combat, While fleeing or In an IDP camp.

\section{Alleged perpetrator:}

Type (Partner, Family member, Known civilian, Unknown civilian, Military or armed group) and number of perpetrators.

\section{Vulnerability factors:}

Destroyed/Lost property and/or income, Mother head of household, Natural death of loved one less than two years ago, Natural death of loved one more than two years ago, Parents missing, Caretaker neglect, Severe or chronic medical/physical condition, Severe or chronic mental health condition, Suffering from stigma due to an illness, Congenital anomaly, Marginalization and social discrimination, Absence of social support network and Forced to flee.

\section{The MHPSS:}

Timing (number of days between latest violence and first consultation), Number of individual sessions received, Number of group sessions received, Length of support (number of days between pre and post assessment).

\section{Pre and post assessments:}


Levels of psychological distress were measured through the Depression, Anxiety and Stress Scale with 21 items (DASS21) or the Impact of Event Scale Revised (IES-R). Daily functioning was measured through the ICRC functionality scale.

\section{Data management and statistical analysis}

All categorical data were numerically coded. Quantitative/continuous variables (i.e. pre- and post- scores) were either kept as such or categorized depending on the type of analysis. Categorization of continuous variables was done either by identifying the median to divide the study participants in two even-sized groups or by using established clinical cut-offs (see section on dataset).

The dataset was created in Microsoft Excel with two independent data clerks to control for potential typing mistakes. The electronic dataset was protected by a password, which was changed every three months. The dataset was transferred to STATA ${ }^{\mathrm{TM}}$, version MP 16.0 for analysis.

All quantitative variables were explored by defining their means (and standard deviation), medians and quartiles. Comparisons of means were tested through the t-test, and the corresponding p-value was reported; $95 \%$ confidence intervals $(95 \% \mathrm{Cl})$ were calculated around means and means differences. Categorical variables were explored through percentages and tested using the $\mathrm{Chi}^{2}$ test to retrieve the corresponding p-value; $95 \%$ Cls were calculated around these percentages.

To measure associations between pre and post scores and the other variables (crude and multivariable), logistic regression models were fitted to calculate odds ratios (OR) with corresponding $95 \% \mathrm{Cls}$ and $\mathrm{p}$ values from the Wald test. All variables were initially explored in a crude model and included in a multivariable model and presented only if statistically significant.

\section{Results}

\section{The study population}

Of the 6,413 victims of violence included in the study, $81 \%(\mathrm{~N}=6,413)$ were from the Democratic Republic of Congo, $3 \%$ from Mali and $16 \%$ from Nigeria. $80 \%$ were female and the mean age was 32 (table 1). The main types of violence experienced by the patients were rape (46\%) and physical violence (42\%). The vast majority of the alleged perpetrators were military or armed groups (76\%). The most common place of violence was on the road (39\%) and in the victim's home (34\%). Additional vulnerability factors mentioned by the patient during the first session included destruction or loss of property or income $(60 \%)$ and being a mother head of household (30\%).

\section{The MHPSS}


The timing of the MHPSS was most commonly 3-14 days following exposure to violence (30\%). The most common length of the support was 15-30 days (25\%) and 31-60 days (23\%). In addition to the first and last sessions consisting of pre and post assessments, patients most commonly received 3-4 individual follow-up session (56\%). Patients receiving group support attended an average of 7 sessions.

\section{Levels of distress and functioning before and after MHPSS}

Prior to receiving MHPSS, symptoms categorized as "extreme" were more prevalent for anxiety (36.38\%) and depression (22.55\%) (table 2).

When comparing pre and post assessments, DASS21 scores improved among $96.58 \%$ of the patients, IES-R scores improved among $92.70 \%$ of the patients and scores on the ICRC functioning scale improved among $82.26 \%$ of the patients (table 3 ).

The largest reduction in symptoms was seen on the IES-R scale with a 75,9\% decrease in mean scores. While very few patients presented "extreme" levels of distress following MHPSS, the majority of patients with "extreme" difficulties in functioning at baseline reported equally "extreme" difficulties at closure (figure 3).

\section{Determinants of high distress and low functioning prior to MHPSS (table 4)}

\section{Depression}

On the DASS21 scale, high symptoms of depression at intake were associated with particular types of violence; namely forced recruitment (aOR 7.95; $p=0.009$ ), witnessing of physical violence (aOR 2.54; $p<0001)$ and rape (aOR 1.50; $p<0.0001)$. Experiencing discrimination or stigma also increased the likelihood of patients reporting high levels of depression at intake (aOR 2.38, $p=0.019)$, as did destruction or loss of property and/or income ( $a O R 1.22, p=0.022)$. Internally displaced beneficiaries were more likely to report high symptoms of depression at intake $(\mathrm{aOR} 2.25 ; \mathrm{pp}<0.0001)$ as were patients referred by family or friends (aOR 1.40; $p=0.023$ ).

\section{Anxiety}

Predictors of high anxiety at intake included high stress (aOR 3.87, $p=<0.0001)$, high depression ( $a O R$ $3.67 ; p=<0.0001)$ and lack of social support (aOR 2.10, $p=<0.0001)$. The profile of the alleged perpetrator of the violence also played a role: Compared to victims of violence committed by the patients' partners, the likelihood of reporting high anxiety at intake was more than three times higher among victims of violence committed by the military or armed groups ( $\mathrm{aOR} 3.51, \mathrm{p}=0.001)$ and more than twice as high 
when the alleged perpetrator was an unknown civilian (aOR 2.76, $p=0.014)$ or a known civilian $(a O R 2.45$, $\mathrm{p}=0.028)$.

\section{Stress}

High stress at baseline correlated with also reporting high depression (aOR 5.23, p=<0.0001) and high anxiety (aOR 3.90, $p=<0.0001$ ). In addition, two types of violence were also strong predictors of high distress: disappearance/abduction of a loved one $(\mathrm{aOR} 4.04 ; \mathrm{p}=0.035)$ and having experienced physical violence $($ aOR $1.49 ;<0.0001)$.

\section{Post-Traumatic Stress}

Looking at the IES-R scale, a linear trend $(a O R$ 1.19; $p=0.009)$ was found between increasing likelihood of reporting high symptoms at intake and increasing age. Females were more than twice as likely than male to report high symptoms of post-traumatic stress at intake (aOR 2.07; $p=<0.0001$ ) and the likelihood was higher among patients having commenced primary education (aOR 1.48; $p=0.005)$ and even higher among patients having commenced secondary education (aOR 3.38, $p=<0.0001$ ). Having experienced particular types of violence increased the likelihood of showing high levels of post-traumatic stress at intake, particularly witnessing the killing of a loved one $(\mathrm{aOR} 1.73 ;<0.0001)$ and witnessing physical violence in general (aOR $1.47 ; 0.004)$.

\section{Functioning}

Predictors of low functioning at baseline included high levels of depression (aOR 1.28, p=0.010), having experienced the destruction or loss of property or income (aOR 1.80, $p=<0.0001)$ and having been a victim of rape (aOR 1.42; $p=0.001)$.

\section{Determinants of improvement following MHPSS (table 5)}

\section{Depression}

A linear trend was observed between the length of the treatment and the likelihood of reducing symptoms of depression. Patients who had experienced the natural death of a loved one more than two years ago were less likely to report reduced depression at closure (aOR $0.26 ; p=<0.0001)$.

\section{Anxiety}


Illiterate patients were less likely to report reduced distress following MHPSS (aOR 1.41, p=0.036). Lack of social support, which was a predictor of high anxiety at baseline, was also a predictor of changes in levels or anxiety following MHPSS. Thus, compared to patients who did not report lacking social support, patients who did report lacking social support were three times less likely to show a large reduction in symptoms of anxiety following MHPSS (aOR $0.27 ; p=>0.0001$ ).

\section{Stress}

A linear trend was observed between the likelihood of showing a large reduction in symptoms of stress and the patient's education level (OR 1.17; $p=0.011)$. Patients that lacked social support were less than half as likely to show reduced stress at closure ( $a O R 0.49 ; p=0.006)$ as were patients who had experienced the natural death of a loved one less than two years ago (aOR $0.46 ; p=<0.0001$ ).

\section{Post-traumatic Stress}

On the IES-R scale, $92.70 \%$ of the patients showed a reduction in symptoms following MHPSS. Experiencing discrimination, stigma and/or marginalization correlated with a smaller or no reduction in symptoms of post-traumatic stress (aOR $0.23 ; p=0.037)$.

\section{Functioning}

A linear trend was found between an increasing number of children and an increasing likelihood of improving daily functioning (aOR 1.05; $\mathrm{p}=0.042$ ). Also, patients who improved functioning the most were less likely than other patients to have experienced a destruction or loss of property and/or income (aOR $0.90 ; p=0.44)$.

\section{Individual versus group sessions}

No significant differences were found with regards to reduced distress or increased functioning following individual versus group sessions. However, whereas the average length of individual psychological support was 49 days, the average length of group psychological support was 131 days. Also, the drop-out rate was lower among beneficiaries of group psychological support in that $61,25 \%$ completed the sessions with a post-assessment compared to only $43,58 \%$ among beneficiaries of individual psychological support.

\section{Discussion}

The various factors correlating with particular levels of symptoms before and after MHPSS can be divided into four sets of determinants related to the beneficiary, the violence experienced, other 


\section{Determinants related to the beneficiary}

Illiteracy stood out as a strong predictor of high levels of depression. One meta-analysis found a similar association between low educational level and an increased likelihood of depression and speculate that people of higher socio-economic status (SES) may have more personal resources such as coping mechanisms and self-esteem that can buffer the impact of exposure to violence and stress on depression. Testing this hypothesis among ICRC weapon-wounded surgical patients would require assessing such personal resources more thoroughly. Following the psychological support, illiterate patients were also less likely to report large reductions in their levels of anxiety and stress. The fact that the better educated beneficiaries improved significantly more on these parameters could indicate that the psychological support, in its current form, favor the better educated patients.

Thus, it would seem relevant to review the current approach to ensure that illiterate patients receive appropriate psychological support to address anxiety and stress in particular.

Internal displacement also correlated with increased likelihood of high depression at baseline. A recent meta-analysis confirmed a link between internal displacement and depression rates of up to $80 \%$. The fact that internal displacement did not influence the outcome of the psychological support suggests that the counseling in its current form adequately addresses the needs of this sub-group of beneficiaries.

The referral pathway played a role in that beneficiaries referred by family members or friends were more likely to present high symptoms of depression at baseline. This suggests that people with the most severe levels of depression are less likely to proactively seek care by themselves and that identifying these beneficiaries through their family and friends is essential to ensuring that they gain access to psychological support. This finding should be taken into consideration when defining strategies for awareness raising. Such activities should target not only potential beneficiaries, but also members of the community who may not need MHPSS services themselves but who can help to identify vulnerable people in their network in need of this type of support.

High levels of post-traumatic distress were associated with increasing age, primary and secondary education level and female gender. While the first two are not consistent with findings of other studies,, the correlation between female gender and increased likelihood of PTSD, including prolonged duration of PTSD, has been shown both in Western and Africa populations.

Unexpectedly, the more children the beneficiary had, the more likely he or she was to show increased functioning following psychological support. The authors are not aware of any studies documenting such an association. It is likely that having more children to take care of pushes the beneficiary out of ruminations and back to doing what is necessary, i.e., functioning. Also, one of the elements of the 
psychological support is to mobilize one's network (including children) to increase practical and emotional support. This may have helped some beneficiaries to more easily carry out everyday tasks.

\section{Determinants related to the violence experienced}

High symptoms of depression correlated with having experienced forced recruitment, rape or witnessing of physical violence. A study of former child soldiers in Uganda found depression to be the most dominant mental health disorder with a prevalence rate of $36 \%$. A systematic review found forced recruitment to increase the risk of both depression and post-traumatic stress disorder (PTSD), despite variations in prevalence rates depending on the methodology used in the various studies.

Consistent with the association between rape and increased likelihood of high symptoms of depression, a systematic review found prevalence rates of depression of up to $76 \%$ among victims of sexual violence in conflict settings. The fact that rape also correlated with low functioning prior to receiving psychological support points to the very tangible consequences that this grave form of sexual violence has on the life of the victims.

Furthermore, consistent with the association between witnessing of physical violence and increased likelihood of high symptoms of depression, a study from a non-humanitarian setting found that witnessing community violence, without ever being a direct victim of physical violence, more than doubled the likelihood of depression.

The profile of the perpetrator as weapon-bearer versus civilian matters not only in terms of ICRC mandate, but also in terms of predicting high levels of anxiety among victims of violence. Indeed, addressing the psychological needs of a victims of violence committed by a member of the military or an armed group with, for example a generalized fear of men in uniforms, differs from addressing the psychological needs of, for example, a victim of domestic violence.

These types of violence correlated with the levels of certain symptoms prior to - but not following psychological support. This indicates that while counselors should be attentive to certain types of violence causing particular psychological needs, by and large the psychological support in its current form does not overlook the needs of beneficiaries having experienced particular types of violence.

\section{Determinants related to other vulnerability factors}

Disappearance of a loved one predicted high levels of stress prior to psychological support. The link between having a missing relative and experiencing psychological distress has been documented in a previous study of ICRC MHPSS programs. Likewise, social stigma was a predictor of depression. One study found stigma has been identified as a mediator between sexual violence and depression in DRC.

Three predictors of high distress and low functioning both before and after receiving psychological support stood out repeatedly (see figure 2): lack of social support, grief and acute financial needs resulting from destruction or loss of property or income. These findings suggest that beneficiaries 
presenting these additional vulnerability factors benefit less from the psychological support that they receive. Consequently, when relevant, the counseling should focus on expanding the network of beneficiaries with limited or no social support and counselors should be attentive to beneficiaries experiencing grief even when caused by factors unrelated to the armed conflict. Also, for beneficiaries with acute financial needs resulting from exposure to violence, psychological support alone does not suffice. For this sub-group of beneficiaries, MHPSS outcomes such as reduced psychological distress, cannot be achieved unless financial needs are addressed in parallel with the psychological support.

\section{Determinants related to the MHPSS received}

The only determinant of improvement which was related to the MHPSS received was the length of the psychological support. No significant difference in improvement was found between beneficiaries receiving individual and group psychological support per se, despite the fact that group support tended to last almost three times longer than individual support. Thus, increasing the length of the psychological support, particularly for the individual support, should be prioritized to ensure that beneficiaries profit as much as possible. This is particularly challenging in conflict settings characterized by limited access and internal displacement.

However, if the aim is truly to make a difference by reducing the psychological distress and increasing the daily functioning of victims of violence, then the barriers to longer-term psychological support must be examined further and addressed. Even from a strict cost-benefit perspective, having already invested in having specialized MHPSS teams on the ground, organizing trainings and supervisions, paying incentives etc., it would make sense to more thoroughly try to understand and address the barriers to longer term treatment adherence.

\section{Strengths and Limitations}

This study was made possible by the extensive monitoring system of ICRC MHPSS programs. The reallife settings, the uniqueness of the data and the large number of beneficiaries involved constitute major strengths of this study. Furthermore, the quality of the data derived from standardized psychometric tools and following each individual patient before and after MHPSS can be considered as important attributes.

The main limitation of this study is the absence of a control group. Therefore, it is not possible to state whether the changes in distress levels were due to the intervention or for other reasons, even if the experience of violence preceded the MHPSS intervention. Another limitation is the fact that all the data used in the study stems from information obtained from the patient him or herself; this may have introduced information bias and possible misclassification. Finally, despite the various variables used to construct the regression models, residual confounding cannot be ruled out.

\section{Conclusion}

Supplemented by MHPSS projects integrated into primary healthcare, hospitals, physical rehabilitation centers and other structures, community-level projects remain a pertinent entry point for reaching the 
broader civilian population affected by armed conflict and other situations of violence.

The main operational recommendations deriving from this study can be summarized as follows:

- Using qualitative methods, explore the link between illiteracy and reduced likelihood of improvement of anxiety and stress following MHPSS.

- Where relevant, ensure greater adaptation of the psychological support to beneficiaries with a low education level.

- Address grief by reinforcing the training counselors on this topic

- Address lack of social support more proactively by enhancing, when relevant, the beneficiary's support network.

- Ensure that acute financial needs resulting from violence are addressed alongside the psychological needs.

- Examine and address the barriers to adherence to treatment, particularly for individual psychological support, to increase the number of follow-up session per patient. Explore the pertinence of reimbursing transportation costs and/or introducing home visits.

- Monitor the content of the psychological support, i.e., techniques used and themes discussed, to be able to pinpoint and reinforce the specific elements that correlated with improvement.

- Conduct an analytical longitudinal study to assess the longer-term levels of distress and functioning following MHPSS.

\section{Declarations}

\section{Ethical approval}

This study has been approved by the Medical Ethics Committee of the Free University of Brussels (VUB) in Brussels, Belgium (B.U.N. 143201942389). The data were not initially collected for research purposes, but as part of the routine monitoring of the ICRC MHPSS sub-unit.

\section{Consent for publication}

$\mathrm{N} / \mathrm{A}$

\section{Availability of data and materials}




\section{Competing interests}

The authors declare no conflict of interest. The authors alone are responsible for the content and writing of the article. The views expressed are those of the authors and do not necessarily represent the views, policies or decisions of their employers.

\section{Funding}

N/A

\section{Authors' contributions}

\begin{tabular}{|lllll|}
\hline & IA & RR & IH \\
\hline Conceived and designed the analysis & & X & \\
\hline Compiled the data & X & & \\
\hline Contributed data or analysis tools & X & X & \\
\hline Performed the analysis & X & & \\
Wrote the paper & X & & \\
\hline Commented and validated the final draft & & $X$ & $X$ \\
\hline
\end{tabular}

\section{Acknowledgements}

The authors wish to thank the entire ICRC MHPSS team and their partners.

\section{Authors' information}

Ida Andersen: Clinical Psychologist

Rodolfo Rossi: Epidemiologist

Ives Hubloue: Medical Doctor

\section{References}


1. Discover the ICRC - Assistance [internet]. Geneva: International Committee of the Red Cross; 2021. Available from : https://app.icrc.org/discover-icrc/5-assistance.html [cited 2021 Jun 18]

2. Violences sexuelles au Congo (RDC) : les victimes sur le banc des accusés. Geneva: International Committee of the Red Cross; 2007. Available from:

https://www.icrc.org/fr/doc/resources/documents/interview/congo-kinshasa-interview-191207.htm [cited 2021 Jun 18]

3. Clinical management of rape and intimate partner violence survivors Developing protocols for use in humanitarian settings. Geneva: World Health Organization; 2020. Available from: https://apps.who.int/iris/bitstream/handle/10665/331535/9789240001411-eng.pdf?ua=1 [cited 2021 Jun 18]

4. Programme/project management: The results-based approach. Geneva: International Committee of the Red Cross; 2008. Available from: https://www.icrc.org/en/doc/resources/documents/publication/p0951.htm accessed on 22.05.2021 [cited 2021 Jun 18]

5. Inter-Agency Standing Committee (IASC) Reference Group for Mental Health and Psychosocial Support in Emergency Settings (2017). A Common Monitoring and Evaluation Framework for Mental Health and Psychosocial Support Programs in Emergency Settings. Geneva: IASC.

6. The International Red Cross and Red Crescent Movement [internet]. Geneva: International Committee of the Red Cross; 2021. Available from: https://www.icrc.org/en/who-we-are/movement [cited 2021 Jun 18]

7. International Federation of Red Cross and Red Crescent Societies (IFRC) Reference Center for Psychosocial Support (PS Centre) (2017). Monitoring and Evaluation Framework for Psychosocial Support Interventions. Copenhagen: IFRC PS Centre.

8. International Red Cross and Red Crescent Movement policy on addressing mental health and psychosocial needs (2019). Geneva: RCRC Movement.

9. https://rcrcconference.org/about/33rd-international-conference/ accessed on 23.05.2021

10. Inter-Agency Standing Committee (IASC) Reference Group for Mental Health and Psychosocial Support in Emergency Settings (2017). A Common Monitoring and Evaluation Framework for Mental Health and Psychosocial Support Programs in Emergency Settings. Geneva: IASC.

11. International Red Cross and Red Crescent Movement policy on addressing mental health and psychosocial needs (2019). Geneva: RCRC Movement.

12. Glossary: Distinction [Internet]. Geneva: International Committee of the Red Cross; 2021. Available from: https://casebook.icrc.org/glossary/distinction [cited 2021 May 24].

13. Andersen, I., Rossi, R., Yabutu, M. N. M., \& Hubloue, I. (2020). Integrating Mental Health and Psychosocial Support Into Health Facilities in Conflict Settings: A Retrospective Review From Six African Countries.Frontiers in public health,8, 892.

14. Andersen, I., Rossi, R., Yabutu, M. N. M., \& Hubloue, I. (2020). Integrating Mental Health and Psychosocial Support Into Health Facilities in Conflict Settings: A Retrospective Review From Six 
African Countries.Frontiers in public health,8, 892.

15. Lorant, V., Deliège, D., Eaton, W., Robert, A., Philippot, P., \& Ansseau, M. (2003). Socioeconomic inequalities in depression: a meta-analysis.American journal of epidemiology,157(2), 98-112.

16. Morina, N., Akhtar, A., Barth, J., \& Schnyder, U. (2018). Psychiatric disorders in refugees and internally displaced persons after forced displacement: a systematic review.Frontiers in psychiatry,9, 433.

17. Charlson FJ, Flaxman A, Ferrari AJ, Vos T, Steel Z, Whiteford HA. Post-traumatic stress disorder and major depression in conflict-affected populations: an epidemiological model and predictor analysis.Glob Ment Health.(2016) 3:E4. doi: 10.1017/gmh.2015.26

18. Lorant, V., Deliège, D., Eaton, W., Robert, A., Philippot, P., \& Ansseau, M. (2003). Socioeconomic inequalities in depression: a meta-analysis.American journal of epidemiology,157(2), 98-112.

19. Luxton, D. D., Skopp, N. A., \& Maguen, S. (2010). Gender differences in depression and PTSD symptoms following combat exposure.Depression and anxiety,27(11), 1027-1033.

20. Mpembi MN, Lukeba T, Mayemba D, Massamba VK, ma Nzuzi TM, Gokara S, et al. États de stress en consultation externe à l'hôpital général de Bangui dans un contexte de conflit armé: étude transversale descriptive.Pan Afr Med J. (2018) 29:1-7. doi: 10.11604/pamj.2018.29.26.7107

21. Klasen, F., Oettingen, G., Daniels, J., \& Adam, H. (2010). Multiple trauma and mental health in former Ugandan child soldiers.Journal of traumatic stress,23(5), 573-581.

22. Betancourt, T. S., Borisova, I., Williams, T. P., Meyers-Ohki, S. E., Rubin-Smith, J. E., Annan, J., \& Kohrt, B. A. (2013). Research Review: Psychosocial adjustment and mental health in former child soldiersa systematic review of the literature and recommendations for future research.Journal of Child Psychology and Psychiatry,54(1), 17-36.

23. Ba, I., \& Bhopal, R. S. (2017). Physical, mental and social consequences in civilians who have experienced war-related sexual violence: a systematic review (1981-2014). Public health,142, 121135.

24. Clark, C., Ryan, L., Kawachi, I., Canner, M. J., Berkman, L., \& Wright, R. J. (2008). Witnessing community violence in residential neighborhoods: a mental health hazard for urban women.Journal of Urban Health,85(1), 22-38.

25. Mandate and mission [Internet]. Geneva: International Committee of the Red Cross; 2021. Available from: https://www.icrc.org/en/mandate-and-mission [cited 2021 May 05].

26. Andersen, I., Poudyal, B., Abeypala, A., Uriarte, C., \& Rossi, R. (2020). Mental health and psychosocial support for families of missing persons in Sri Lanka: a retrospective cohort study.Conflict and health, 14, 1-15.

27. Verelst, A., De Schryver, M., De Haene, L., Broekaert, E., \& Derluyn, I. (2014). The mediating role of stigmatization in the mental health of adolescent victims of sexual violence in Eastern Congo. Child Abuse \& Neglect, 38(7), 1139-1146.

\section{Tables}


Table 1

Characteristics of the study population and the MHPSS

Page 19/35 


\section{Country $(\mathrm{N}=6,413)$}

Democratic Republic of the Congo

$5,190 \quad 80.93$

Mali

$184 \quad 2.87$

Nigeria

1,039

16.20

\section{Gender $(\mathrm{N}=6,287)$}

Male

$1,238 \quad 19.69$

Female

$5,049 \quad 80.31$

Age $(N=6,345)$

0-17

550

8.67

$18-24$

$1,178 \quad 18.57$

25-34

$2,172 \quad 34.23$

$35-44$

$1,450 \quad 22.85$

45-81

995

15.68

\section{Civil status $(\mathrm{N}=6,220)$}

Single (incl. children)

$1,401 \quad 22.52$

Married

$3,601 \quad 57.89$

Partner abroad

$22 \quad 0.35$

Partner missing

$72 \quad 1.16$

Divorced/Separated

350

5.63

Widow/er

721

11.59

Other

53

0.85

\section{Resident-Migrant/IDP status $(\mathrm{N}=6,104)$}

Resident

$4,437 \quad 72.69$

Internally displaced

$1,633 \quad 27.31$

\section{Education level $(\mathrm{N}=6,190)$}

Illiterate

Basic

$2,402 \quad 38.80$

Medium

$1,668 \quad 26.95$

High 
Occupation $(6,412)$

Unemployed

Student

624

9.73

Farming/cattle

3,160

49.28

Shop/business

$1,210 \quad 18.87$

Other jobs

$1,284 \quad 20.02$

\section{Number of children $(\mathrm{N}=5,514)$}

0

879

15.94

1

305

5.53

2

516

9.36

3

659

11.95

4

723

13.11

5

700

12.69

6

632

11.46

$7-20$

1,100

19.95

\section{Type of violence experienced $(\mathrm{N}=6,413)$}

Victim of physical violence excluding rape, attempted rape and torture

$2,718 \quad 42,38$

Witness of physical violence

$1,352 \quad 21,08$

Rape

$3,937 \quad 45.80$

Attempted rape

Incest

$262 \quad 4.09$

Forced marriage

571

8.90

Forced prostitution

24

0.37

Victim of trafficking/smuggling

Kidnapping/hostage taking including sexual violence

Kidnapping/hostage taking excluding sexual violence

Killing of a loved one

Disappearance of a loved one

Forced recruitment

Torture/ill-treatment 


\section{Alleged perpetrator $(\mathrm{N}=6,011)$}

Partner

Family member

Known civilian (non-family member)

508

8.45

Unknown civilian

$616 \quad 10.25$

Military or armed group

$4,564 \quad 75,93$

No information

57

0.95

Other factors of vulnerability highlighted by the patient during the first session (not mutually exclusive) $(\mathrm{N}=6,413)$

Destroyed/Lost property and/or income

Mother head of household

$3,879 \quad 60.49$

Natural death of loved one less than two years ago

Natural death of loved one more than two years ago

Parents missing

Caretaker neglect

Severe or chronic medical/Physical condition

Severe or chronic mental health condition

Suffering from stigma due to an illness

Congenital anomaly

Marginalization and social discrimination

Absence of social support network

Forced to flee

\section{Number of perpetrators $(\mathrm{N}=5,598)$}

None

One

Several

$3,919 \quad 70.01$

\section{Place of violence $(\mathrm{N}=6,025)$}

Home 


\begin{tabular}{|c|c|c|}
\hline School/Work & 897 & 14.89 \\
\hline On the road/While going somewhere & 2,323 & 38.56 \\
\hline During combat & 145 & 2.41 \\
\hline While fleeing & 194 & 3.22 \\
\hline In an IDP camp & 10 & 0.17 \\
\hline Other & 410 & 6.95 \\
\hline \multicolumn{3}{|c|}{ Timing: Days between latest violence and first consultation $(\mathrm{N}=3,322)$} \\
\hline $0-2$ & 361 & 10.87 \\
\hline $3-14$ & 991 & 29.83 \\
\hline $15-90$ & 770 & 23.18 \\
\hline $91-365$ & 285 & 8.58 \\
\hline$<365$ & 915 & 27.54 \\
\hline \multicolumn{3}{|c|}{ Number of individual sessions excluding pre- and post-assessments $(\mathrm{N}=1,319)$} \\
\hline \multicolumn{3}{|l|}{$1-2$} \\
\hline $3-4$ & 95 & 7.20 \\
\hline $5-6$ & 741 & 56.18 \\
\hline \multirow[t]{2}{*}{$7-10$} & 460 & 34.87 \\
\hline & 23 & 1.74 \\
\hline \multicolumn{3}{|c|}{ Number of group sessions excluding pre- and post-assessments ( $\mathrm{N}=691)$} \\
\hline $1-2$ & 82 & 11.87 \\
\hline $3-4$ & 82 & 11.87 \\
\hline $5-6$ & 154 & 22.29 \\
\hline $7-12$ & 373 & 53.98 \\
\hline \multicolumn{3}{|c|}{ Length of MHPSS: Days between pre- and post-assessment $(\mathrm{N}=2,268)$} \\
\hline$<8$ & 95 & 4.19 \\
\hline $8-14$ & 135 & 5.95 \\
\hline $15-30$ & 561 & 24.74 \\
\hline $31-60$ & 516 & 22.75 \\
\hline $61-90$ & 316 & 13.93 \\
\hline $91-120$ & 343 & 15.12 \\
\hline
\end{tabular}




\section{Table 2}

Distress and Functioning categories

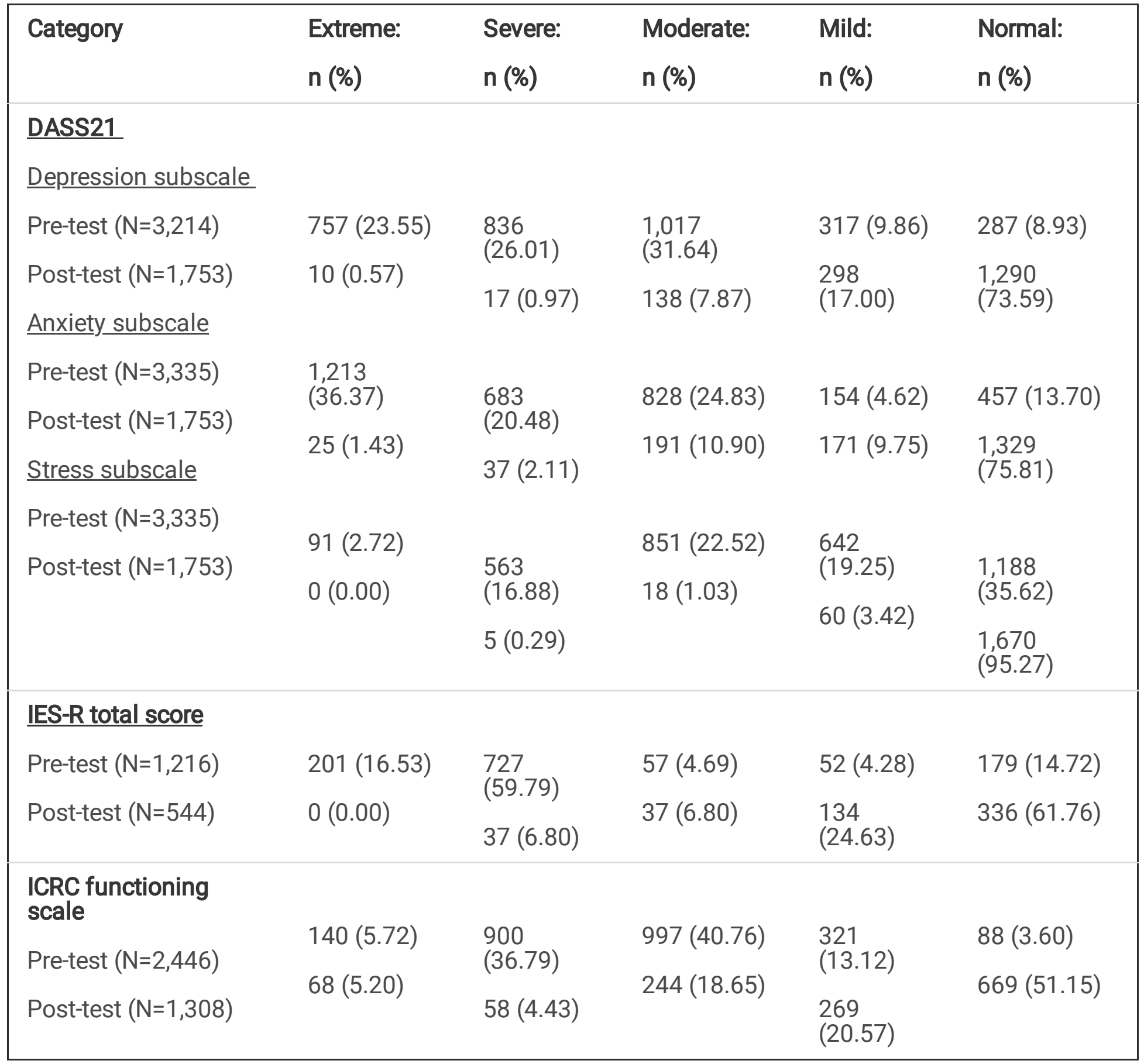


Distress and Functioning Pre- and Post-Scores

\begin{tabular}{|c|c|c|c|c|c|c|}
\hline & $\begin{array}{l}\text { Mean } \\
\text { (SD) }\end{array}$ & $95 \% \mathrm{Cl}$ & p-value & Range & $\begin{array}{l}\text { Med } \\
\text { (IQR) }\end{array}$ & $\begin{array}{l}\% \\
\text { who improved }\end{array}$ \\
\hline Pre-DASS $(\mathrm{N}=3,214)$ & $\begin{array}{l}55.66 \\
(20.62)\end{array}$ & $\begin{array}{l}54.9 \\
56.38\end{array}$ & & $2-126$ & $\begin{array}{l}56(42 \\
-70)\end{array}$ & \\
\hline Post-DASS $(\mathrm{N}=1,753)$ & $\begin{array}{l}17.49 \\
(12.68)\end{array}$ & $\begin{array}{l}16.89 \\
18.08\end{array}$ & & $2-88$ & $\begin{array}{l}16(8- \\
24)\end{array}$ & \\
\hline $\begin{array}{l}\text { DASS difference } \\
(\mathrm{N}=1,669)\end{array}$ & $\begin{array}{l}-36.71 \\
(19.18)\end{array}$ & $\begin{array}{l}-37.64 \\
-35.79\end{array}$ & $<0.0001$ & $\begin{array}{l}-86- \\
26\end{array}$ & $\begin{array}{l}-38(-48 \\
--24)\end{array}$ & 96.58 \\
\hline Pre-IES $(\mathrm{N}=1,216)$ & $\begin{array}{l}46.90 \\
(18.87)\end{array}$ & $\begin{array}{l}45.86 \\
47.94\end{array}$ & & $0-84$ & $\begin{array}{l}50(40 \\
-60)\end{array}$ & \\
\hline Post-IES (N=986) & $\begin{array}{l}11.30 \\
(13.20)\end{array}$ & $\begin{array}{l}10.47 \\
12.12\end{array}$ & & $0-63$ & $\begin{array}{l}20(11 \\
-27)\end{array}$ & \\
\hline IES difference $(\mathrm{N}=986)$ & -34.91 & $\begin{array}{l}-36.12 \\
-33.69\end{array}$ & $<0.0001$ & $\begin{array}{l}-74- \\
26\end{array}$ & $\begin{array}{l}-37(-50 \\
--20)\end{array}$ & 92.70 \\
\hline $\begin{array}{l}\text { Pre-Functioning } \\
(\mathrm{N}=2,447)\end{array}$ & $\begin{array}{l}6,20 \\
(0.06)\end{array}$ & $6.09 ; 6.31$ & & $2-14$ & $\begin{array}{l}6(4- \\
8)\end{array}$ & \\
\hline $\begin{array}{l}\text { Post-Functioning } \\
(\mathrm{N}=1,309)\end{array}$ & $\begin{array}{l}10,47 \\
(0.10)\end{array}$ & $\begin{array}{l}10.28 \\
10.67\end{array}$ & & $2-14$ & $\begin{array}{l}12(8- \\
14)\end{array}$ & \\
\hline $\begin{array}{l}\text { Functioning difference } \\
(\mathrm{N}=1,302)\end{array}$ & $\begin{array}{l}4.40 \\
(3.66)\end{array}$ & $4.20 ; 4.60$ & $<0.0001$ & $-7-12$ & $4(2-7)$ & 82.26 \\
\hline
\end{tabular}

Table 4

Factors associated with high distress and low functioning at baseline 


\section{DEPRESSION (DASS21)}

Education level $(\mathrm{N}=3,117)$

Illiterate

Ref

- Ref

Basic

0.95 (0.80;

1.12)

0.538

0.88 (0.71;

1.08)

Medium

0.85 (0.71;

High

1.02)

0.080

0.897

0.76 (0.61;

$0.95)$

0.016

0.94 (0.37;

2.39)

0.93 (0.28;

3.14)

High anxiety at baseline $(\mathrm{N}=3,214)$

No

Ref

$6.13(5.24 ; \quad<0.0001$

Yes

7.14)

Ref

$3.77(3.13 ; \quad<0.0001$ 4.54)

High stress at baseline $(\mathrm{N}=3,214)$

No

Yes

Ref

$7.91(6.74$;

9.28)

$<0.0001$

Ref

$-$

Other vulnerability factors

(Ref=Not reported) $(\mathrm{N}=3,214)$

Destroyed/lost property and/or income

Experience of discrimination/stigma

$\begin{array}{llll}1.35(1.17 ; & <0.0001 & 1.22(1.03 ; & 0.022 \\ 1.55) & & 1.46) & 0.019 \\ 2.49(1.41 ; & 0.002 & & 2.38(1.15 ; \\ 4.41) & & 4.94) & \end{array}$

Referral pathway $(\mathrm{N}=3,212)$

Self-referred

Referred by family or friends

$\begin{array}{llll}\text { Ref } & - & \text { Ref } & - \\ 1.23(0.98 ; & 0.077 & 1.40(1.05 ; & 0.023 \\ 1.56) & & 1.87) & \end{array}$

Internally displaced $(\mathrm{N}=3,119)$

No

Ref

5.27 (4.39;

$<0.0001$ $6.32)$

0.0001

Yes

$\begin{array}{lll}2.29(1.82 ; & <0.0001 & 2.25(1.70 ; \\ 2.87) & 2.97)\end{array}$

\section{Type of violence experienced ( $\mathrm{Ref}=\mathrm{Not}$} reported) $(\mathrm{N}=3,214)$ 


$\begin{array}{|lllll|}\text { Forced recruitment } & 9.77(2.27 ; & 0.002 & 7.95(1.69 ; & 0.009 \\ \text { Rape } & 42.02) & 0.011 & 37.47) & <0.0001 \\ \text { Witnessing physical violence } & 1.20(1.04 ; & & 1.50(1.25 ; & <0.0001 \\ & 1.38) & <0.0001 & 1.80) & \\ & 1.86(1.45 ; & & 2.54(1.83 ; & \\ & 2.38) & & 3.52) & \end{array}$

\section{ANXIETY (DASS21)}

\section{Alleged perpetrator $(\mathrm{N}=3,213)$}

Partner

Family member

Known civilian

Unknown civilian

Military or armed group
Ref

1.19 (0.58; $\quad 0.631$

2.46)

$1.41(0.73$

2.73)

$1.74(0.90 ;$

3.38)

2.51 (1.35;

4.69)
0.310

0.102

0.004
Ref

1.51 (0.63;

3.63)

2.45 (1.10;

5.48)

2.76 (1.23;

6.18)

$3.51(1.64$

7.50)

\section{High depression at baseline $(\mathrm{N}=3,214)$}

No

Yes
Ref

$6.13(5.24$

7.17) $-\quad$ Ref

$<0.0001$

3.67 (3.07; 4.39)

High stress at baseline $(\mathrm{N}=3,335)$

No

Ref

$7.11(6.10 ;$

8.29)

$-\quad$ Ref

$<0.0001$

3.87 (3.25; 4.62)

$-$

0.356 0.028 0.014 0.001

Yes

Other vulnerability factors:

Lack of social support $(\mathrm{N}=3,335)$

No

Ref

$-\quad$ Ref

Yes

$1.77(1.27 ; \quad 0.001$

2.48)

2.10 (1.39;

$<0.0001$

3.17)

\section{STRESS (DASS21)}

High depression at baseline $(\mathrm{N}=3,214)$

No

Ref

7.91 (6.74;

9.28)

$\begin{array}{lll}- & \text { Ref } & - \\ <0.0001 & 5.23(4.41 ; & <0.0001 \\ & 6.20) & \end{array}$

High anxiety at baseline $(\mathrm{N}=3,335)$ 


\begin{tabular}{|c|c|c|c|c|}
\hline No & Ref & - & Ref & - \\
\hline Yes & $\begin{array}{l}7.11(6.09 ; \\
8.29)\end{array}$ & $<0.0001$ & $\begin{array}{l}3.90 \text { (3.29; } \\
4.62)\end{array}$ & $<0.0001$ \\
\hline \multicolumn{5}{|l|}{ Type of violence experienced } \\
\hline \multicolumn{5}{|l|}{ (Ref=Not Reported) $(\mathrm{N}=3,335)$} \\
\hline \multirow{2}{*}{$\begin{array}{l}\text { Physical violence } \\
\text { Disappearance/abduction of a loved one }\end{array}$} & $\begin{array}{l}1.29(1.11 ; \\
1.49)\end{array}$ & \multirow{2}{*}{$\begin{array}{l}0.001 \\
0.145\end{array}$} & $\begin{array}{l}1.49(1.24 ; \\
1.78)\end{array}$ & \multirow{2}{*}{$\begin{array}{l}<0.0001 \\
0.035\end{array}$} \\
\hline & $\begin{array}{l}1.68(0.84 ; \\
3.37)\end{array}$ & & $\begin{array}{l}4.04(1.10 ; \\
14.78)\end{array}$ & \\
\hline \multicolumn{5}{|l|}{ POST-TRAUMATIC STRESS (IES-R) } \\
\hline \multicolumn{5}{|l|}{ Age $(N=1,210)$} \\
\hline $0-17$ & Ref & - & Ref & - \\
\hline $18-24$ & $\begin{array}{l}5.29 \text { (1.14; } \\
24.59)\end{array}$ & & $\begin{array}{l}5.61 \text { (1.14; } \\
27.50)\end{array}$ & 0.034 \\
\hline $25-34$ & 7.93 (1.79. & 0.006 & $8.91(1.91$ : & 0.005 \\
\hline $35-44$ & $35.17)$ & 0.005 & $41.59)$ & 0.004 \\
\hline \multirow[t]{2}{*}{$45-81$} & $\begin{array}{l}8.64(1.95 \\
38.32)\end{array}$ & 0.012 & $\begin{array}{l}9.59(2.05 ; \\
44.81)\end{array}$ & \multirow[t]{2}{*}{0.004} \\
\hline & $\begin{array}{l}6.81(1.54 ; \\
30.23)\end{array}$ & & $\begin{array}{l}9.72(2.07 ; \\
45.56)\end{array}$ & \\
\hline \multicolumn{5}{|l|}{ Gender $(N=1,214)$} \\
\hline Male & Ref & - & Ref & - \\
\hline Female & $\begin{array}{l}1.86(1.43 ; \\
2.42)\end{array}$ & $<0.0001$ & $\begin{array}{l}2.07(1.60 ; \\
2.94)\end{array}$ & $<0.0001$ \\
\hline \multicolumn{5}{|l|}{ Education level $(\mathrm{N}=1,160)$} \\
\hline Illiterate & Ref & - & Ref & - \\
\hline Basic & $\begin{array}{l}1.44(1.11 ; \\
1.85)\end{array}$ & 0.006 & $\begin{array}{l}1.48(1.12 ; \\
1.94)\end{array}$ & 0.005 \\
\hline Medium & $315(195$. & $<0.001$ & & $<0.0001$ \\
\hline \multirow[t]{2}{*}{ High } & $5.08)$ & 0.078 & $5.64)$ & 0.060 \\
\hline & $\begin{array}{l}1.65(0.95 \\
2.89)\end{array}$ & & $\begin{array}{l}1.78(0.98 \\
3.24)\end{array}$ & \\
\hline \multicolumn{5}{|l|}{ Other vulnerability factors } \\
\hline \multicolumn{5}{|l|}{ (Ref=Not reported) $(\mathrm{N}=1,216)$} \\
\hline Lack of social support & $\begin{array}{l}2,60(1,69 ; \\
3.99)\end{array}$ & $<0.0001$ & $\begin{array}{l}2.04(1.29 \\
3.22)\end{array}$ & 0.002 \\
\hline
\end{tabular}


Type of violence experienced

(Ref=Not reported) $(\mathrm{N}=1,216)$

Killing of a loved one

Witness to physical violence

$$
\begin{array}{llll}
2.15(1.71 ; & <0.0001 & 1.73(1.35 ; & <0.0001 \\
2.71) & <.22) & 0.004 \\
1.69(1.27 ; & & 1.47(1.13 ; & \\
2.25) & & 1.91) &
\end{array}
$$

\section{FUNCTIONING (ICRC Africa scale)}

High depression at baseline $(\mathrm{N}=1,902)$

No

Ref

- $\quad$ Ref

Yes

$1.31(1.09$

1.57)

0.004

1.28 (1.06;

\section{Other vulnerability factors}

(Ref=Not reported $(\mathrm{N}=2,447)$

$\begin{array}{lllll}\text { Destroyed/lost property and/or income } & 1.77(1.51 ; & <0.0001 & 1.80 \\ & 2.09) & & 2.17) & \end{array}$

\section{Type of violence experienced}

(Ref=Not reported) $(\mathrm{N}=2,447)$

Rape

$1.05(0.89$

1.25)

0.540

$1.42(1.16$;

0.001

1.74)

cOR: crude odds ratio; aOR: adjusted odds ratio; p-value from Wald test; DASS21 Depression cut-off: 20; DASS21 Anxiety cut-off: 16; DASS21 Stress cut-off: 18; IES-R cut-off: 51; Functioning cut-off: 5.

\section{Table 5}

Factors associated with improved distress and functioning following MHPSS 


$\begin{array}{lllll}\text { Variables } & \text { cOR }(95 \% \mathrm{Cl}) & \text { p-value } & \underset{(95 \% \mathrm{Cl})}{\mathrm{aOR}} & \text { p-value } \\ & & & \end{array}$

\section{DEPRESSION (DASS21)}

High depression at baseline $(\mathrm{N}=1,669)$

No

Yes
Ref

$15.13(11.92 ; \quad<0.0001$ 19.20)
Ref

12.72

(9.57;

16.90)

\section{Large improvement in symptoms of anxiety}

$(\mathrm{N}=1,669)$

No

Yes
Ref

$5.06(4.11$ $6.24)$

$\begin{array}{lll}- & \text { Ref } & - \\ <0.0001 & 2.42(1.82 ; & <0.0001 \\ 3.22) & \end{array}$

\section{Large improvement in symptoms of stress}

$(\mathrm{N}=1,669)$

No

Yes

$\begin{array}{llll}\text { Ref } & - & \text { Ref } & - \\ \text { 6.08 (4.92; } & <0.0001 & 2.71(2.05 ; & <0.0001 \\ 7.52) & & 3.60) & \end{array}$

Other vulnerability factors:

Natural death of loved one more than two years ago $(N=1,669)$

No

Yes
Length of MHPSS: Days between pre-and post-assessment $(\mathrm{N}=1,552)$

$<8$

8-14

$15-30$

$31-60$

$61-90$

91-120

$121-150$
Ref

$1.91(0.96$

3.78)

4.90 (2.70;

8.89)

$3.23(1.77$;

$5.88)$

$2.99(1.61$

5.54)
- $\quad$ Ref

$<0.0001$

$0.26(0.16$; 0.43)

$<0.0001$

-




\begin{tabular}{|c|c|c|}
\hline $\begin{array}{l}3.52(1.80 \\
6.85)\end{array}$ & 0.004 & $\begin{array}{l}3.66(1.57 \\
8.50)\end{array}$ \\
\hline $\begin{array}{l}3.66(1.55 \\
8.65)\end{array}$ & & $\begin{array}{l}2.77(0.92 ; \\
8.33)\end{array}$ \\
\hline $\begin{array}{l}3.48 \text { (1.48; } \\
8.17)\end{array}$ & & $\begin{array}{l}2.04(0.70 \\
5.97)\end{array}$ \\
\hline
\end{tabular}

ANXIETY (DASS21)

High anxiety at baseline $(\mathrm{N}=1,669)$

No

$\begin{array}{llll}\text { Ref } & - & \text { Ref } & - \\ 17.28(13.49 ; & <0.0001 & 18.73 & <0.0001 \\ 22.12) & & (14.42 ; & \\ & & 24.34) & \end{array}$

Education level $(\mathrm{N}=1,616)$

Illiterate

Ref

$-\quad$ Ref

Basic

$1.10(0.86$

1.40)

0.454

0.99 (0.73;

0.972

Medium

1.33 (1.03;

High

1.71)

0.026

0.345

1.36)

1.41 (1.02;

0.036

$1.66(0.58$;

4.74)

1.94)

0.771

1.22 (0.33;

4.52)

Other vulnerability factors:

Lack of social support $(\mathrm{N}=1,669)$

No

Ref

$-$

Ref

$-$

Yes

0.59 (0.38;

$0.91)$

0.018

$0.27(0.16$;

$<0.0001$

STRESS (DASS21)

High stress at baseline $(\mathrm{N}=1,669)$

No

Ref

21.48 (16.46; 28.03) $0.45)$

Yes

$\begin{array}{lll}- & \text { Ref } & - \\ <0.0001 & 25.85 & <0.0001 \\ & (19.47 ; & \\ & 34.33) & \end{array}$

Education level $(\mathrm{N}=1,616)$

Illiterate

Ref

- $\quad$ Ref

Basic

Medium

$1.01(0.79$;

1.30)

0.919

0.029

High

1.32 (1.03;

1.70)

0.104

1.14 (0.83;

1.56)

0.429

0.003

1.65 (1.19;

2.30)

0.042 
Other vulnerability factors (Ref=Not reported)

$(\mathrm{N}=1,616)$

Lack of social support

Natural death of loved one less than two years ago

\begin{tabular}{|c|c|c|c|}
\hline $\begin{array}{l}0.88(0.57 \\
1.35)\end{array}$ & 0.548 & $\begin{array}{l}0.49(0.28 \\
0.81)\end{array}$ & 0.006 \\
\hline $\begin{array}{l}0.74(0.54 ; \\
1.01)\end{array}$ & 0.054 & $\begin{array}{l}0.46(0.31 ; \\
0.68)\end{array}$ & $<0.0001$ \\
\hline
\end{tabular}

\section{POST-TRAUMATIC STRESS (IES-R)}

High post-traumatic stress at baseline $(\mathrm{N}=544)$

No

Yes

$\begin{array}{llll}\text { Ref } & - & \text { Ref } & - \\ 2.80(1.98 ; & <0.0001 & \begin{array}{l}1.55(1.03 ; \\ 2.33)\end{array} & 0.035 \\ 3.97) & & 2.35\end{array}$

Migrant $(\mathrm{N}=468)$

No

Ref

$4.65(2.18 ; \quad<0.0001$

Ref

$-$

Yes

9.89)

$4.02(1.84 ; \quad<0.0001$

\section{Experience of discrimination/}

stigma/marginalization

No

Yes

$\begin{array}{llll}\text { Ref } & - & \text { Ref } & - \\ 0.38(0.10 ; & 0.161 & \begin{array}{l}0.23(0.06 ; \\ 0.92)\end{array} & 0.037 \\ 1.47) & & \end{array}$

\section{Occupation}

Unemployed

Shop or business owner

Ref

$0.16(0.06 ; \quad 0.001$

$0.46)$

8.80)

\section{FUNCTIONING (ICRC Africa scale)}

Low functioning prior to MHPSS $(\mathrm{N}=1,302)$

No

Yes

$\begin{array}{llll}\text { Ref } & - & \text { Ref } & - \\ 1.92(1.53 ; & <0.0001 & 1.92(1.51 ; & <0.0001 \\ 2.40) & & 2.44) & \end{array}$




\section{Other vulnerability factors:}

Destroyed/lost property and/or income $(\mathrm{N}=1,302)$

No

Yes

$\begin{array}{llll}\text { Ref } & - & \text { Ref } & - \\ 0.87(0.69 ; & 0.199 & \begin{array}{l}0.90(0.71 ; \\ 1.08)\end{array} & 0.044 \\ 1.04 & \end{array}$

cOR: crude odds ratio; aOR: adjusted odds ratio; p-value from Wald test; DASS21 Depression cut-off: -14; DASS21 Anxiety cut-off: -12; DASS21 Stress cut-off: -12; IES-R cut-off: -37; Functioning cut-off: 4.

\section{Figures}

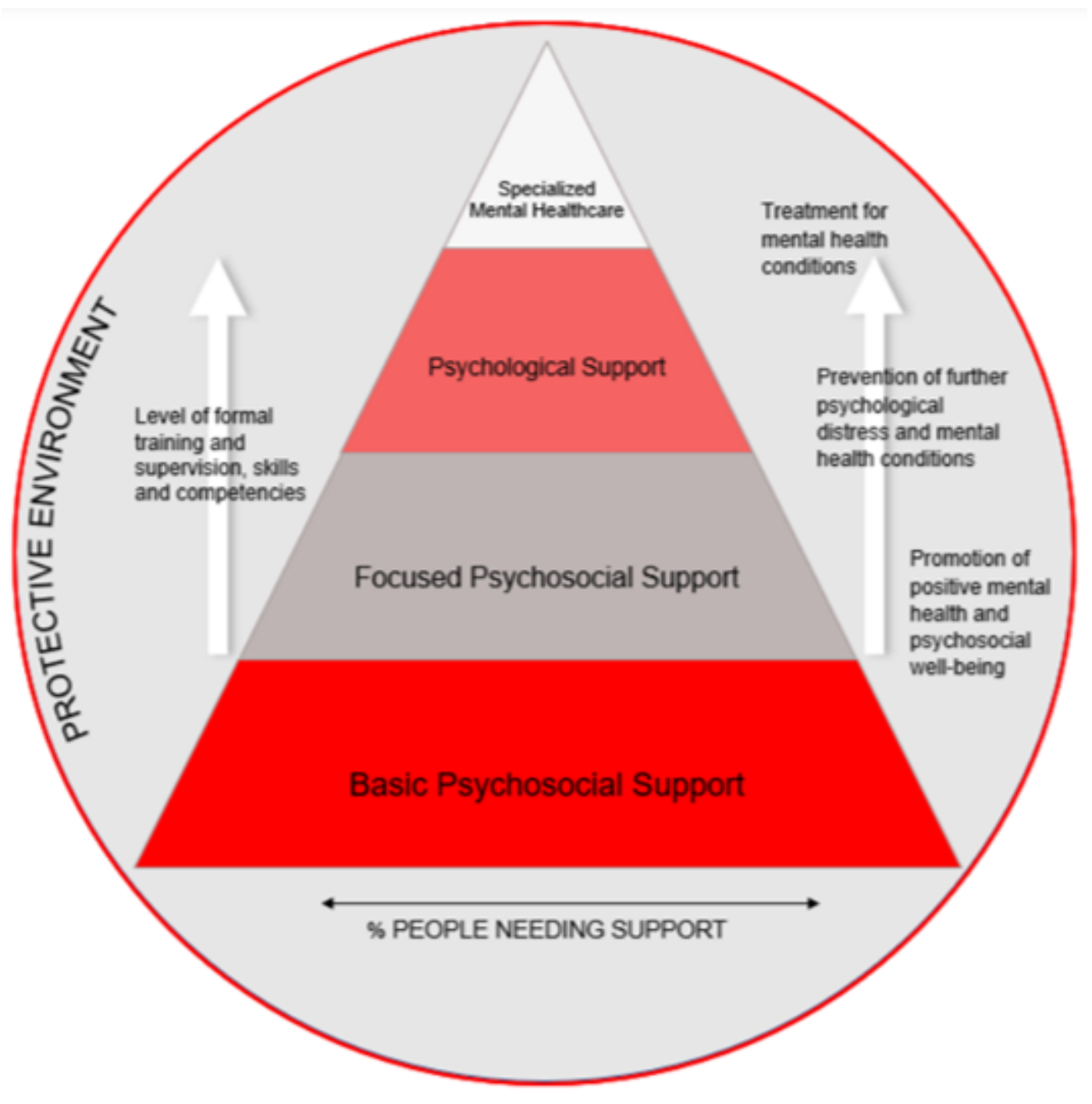

Figure 1 


\section{IES-R DASS21 DASS21 DASS 21 ICRC total Depression Anxiety Stress Functioning}

$\begin{array}{lccccc}\text { Normal } & 0-23 & 0-9 & 0-7 & 0-14 & 0-2 \\ \text { Mild } & 24-32 & 10-13 & 8-9 & 15-18 & 3-5 \\ \text { Moderate } & 33-38 & 14-20 & 10-14 & 19-25 & 6-8 \\ \text { Severe } & 39-63 & 21-27 & 15-19 & 26-33 & 9-11 \\ \text { Extremely severe } & 64-88 & 29+ & 20+ & 34+ & 12-14\end{array}$

Figure 2

Categorization of IES-R, DASS 21 and ICRC functioning scores used in this study

\section{Pre and post symptom categories}

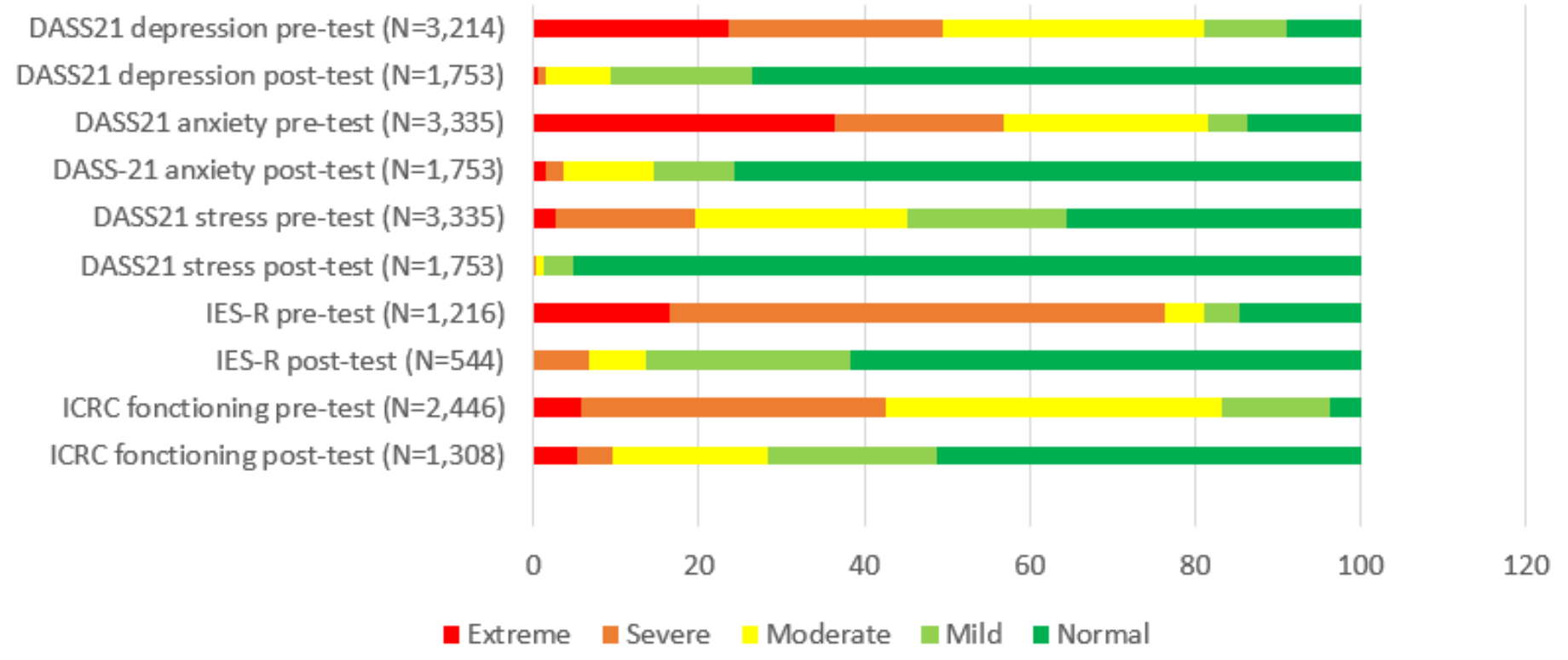

\section{Figure 3}

Pre and post symptom categories 


\begin{tabular}{|c|c|c|c|c|c|}
\hline & \multicolumn{5}{|c|}{ Symptom clusters } \\
\hline $\begin{array}{l}\text { The beneficiary } \\
\text { Age (increasing) } \\
\text { Basic or medium education level } \\
\text { Female gender } \\
\text { Illiteracy } \\
\text { Internally displaced } \\
\text { Number of children (increasing) } \\
\text { Referred by family or friends } \\
\text { Violence Experienced } \\
\text { Forced recruitment } \\
\text { Killing of a loved one } \\
\text { Perpetrator military/ armed group } \\
\text { Physical violence } \\
\text { Rape } \\
\text { Witnessing physical violence } \\
\text { Other vulnerability factors } \\
\text { Destruction/loss property/income } \\
\text { Disappearance of a loved one } \\
\text { Discrimination/stigma } \\
\text { Natural death of a loved one } \\
\text { Lack of social support } \\
\text { MHPSS Received } \\
\text { Treatment length } \\
\text { (1-4 months vs }>7 \text { days) }\end{array}$ & $\begin{array}{l}\text { Depression } \\
\text { 个 pre } \\
\uparrow \text { pre } \\
\uparrow \text { pre } \\
\uparrow \text { pre } \\
\uparrow \text { pre } \\
\uparrow \text { pre } \\
\uparrow \text { post }\end{array}$ & $\begin{array}{l}\text { Anxiety } \\
\text { 个 post } \\
\\
\uparrow \text { pre } \\
\\
\uparrow p r e \\
\uparrow p o s t \\
\uparrow p\end{array}$ & 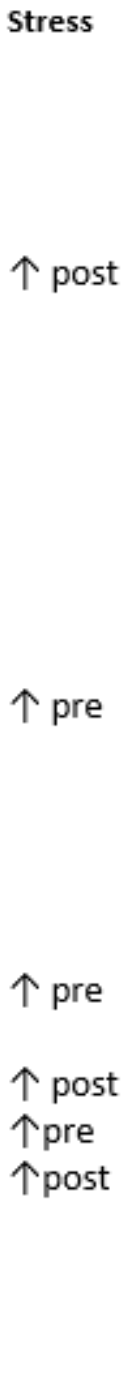 & $\begin{array}{l}\text { PTSD } \\
\uparrow \text { pre } \\
\uparrow \text { pre } \\
\uparrow \text { pre }\end{array}$ & $\begin{array}{l}\uparrow \text { post } \\
\downarrow \text { pre } \\
\downarrow \text { pre } \downarrow \text { post }\end{array}$ \\
\hline
\end{tabular}

Figure 4

Summary of the main determinants

\section{Supplementary Files}

This is a list of supplementary files associated with this preprint. Click to download.

- 2021CommunityforConflictandHealth.xIsx 